\title{
Sure Shot Technique for Management of Ranula
}

\author{
Chiranjib Das, ${ }^{1}$ Pritam Chatterjee ${ }^{2}$
}

\section{Introduction}

ABSTRACT

Ranula is a pseudocyst in the floor of the mouth originating from the sublingual salivary gland. A variety of surgical procedures have been quoted in the literature. But the main concern is high rate of recurrence. Aim of the present study is to describe a definitive technique for managing ranula and compare the result with review of literature.

Materials and Methods

A prospective study was done in the department of ENT in a tertiary care hospital of West Bengal from 1st April, 2014 to 31st March, 2019. Patients presenting with ranula irrespective of age and sex; size of the mass; whether primary or recurrent case were included in the study. Patients presenting with congenital and plunging ranula were excluded. Patients were treated with total excision of ranula along with sublingual salivary gland. Patients were followed up regularly for at least one year post-operatively.

\section{$\underline{\text { Results }}$}

We treated thirteen primary and four recurrent cases of ranula. Among them eight were male and nine were female. Patients were from seven to thirty three years of age with most being in the second decade of life. There was no injury to lingual nerve or submandibular duct in any patient. We did not observe any recurrence till date.

\section{Conclusion}

Successful management of a ranula includes identification of the extent of the cyst and removal of the cyst along with the sublingual salivary gland. When done meticulously, this technique gives $100 \%$ success without any complication.

$\underline{\text { Kevwords }}$

Ranula; Sublingual Gland

$\mathrm{T}$ The word ranula has been derived from the latin word "Rana" which means the frog. This is because it resembles the translucent belly of a frog. ${ }^{1}$ Ranula refers to a pseudocyst in the floor of the mouth originating from the sublingual salivary gland. ${ }^{2}$ It is called pseudocyst, as it does not contain an epithelial lining. ${ }^{3}$ Two variants of ranula have been described in the literature: simple ranula and plunging ranula. Simple ranulas remain confined to the sublingual space, whereas plunging ranulas extend behind the posterior edge of mylohyoid muscle to present in the neck. ${ }^{4}$ In general they are asymptomatic, well circumscribed, fluctuant, bluish coloured swelling present in the floor of the mouth. The mass may interfere with speech, mastication, and swallowing due to the upward and medial displacement of the tongue.

In very rare occasions it may cause respiratory obstruction. ${ }^{4}$ The diagnosis of a ranula can be made by a combination of history, clinical presentation, imaging studies and histopathological examination. A variety of surgical procedures have been quoted in the literature. But the main concern is high rate of recurrence. Aim of the present study is to describe a definitive technique for managing ranula and compare the result with review of literature.

\section{Materials and Methods}

A prospective study was done in the department of ENT in a tertiary care hospital of West Bengal from 1st April,

1 - Department of ENT, Coochbehar Government Medical
College and Hospital, Coochbehar, West Bengal
2 - Department of ENT, Bankura Sammilani Medical
College \& Hospital, Bankura, West Bengal
Corresponding author:
Dr Pritam Chatterjee
email: syroox@gmail.com

College and Hospital, Coochbehar, West Bengal 2 - Department of ENT, Bankura Sammilani Medical College \& Hospital, Bankura, West Bengal

Dr Pritam Chatterjee

email: syroox@gmail.com 


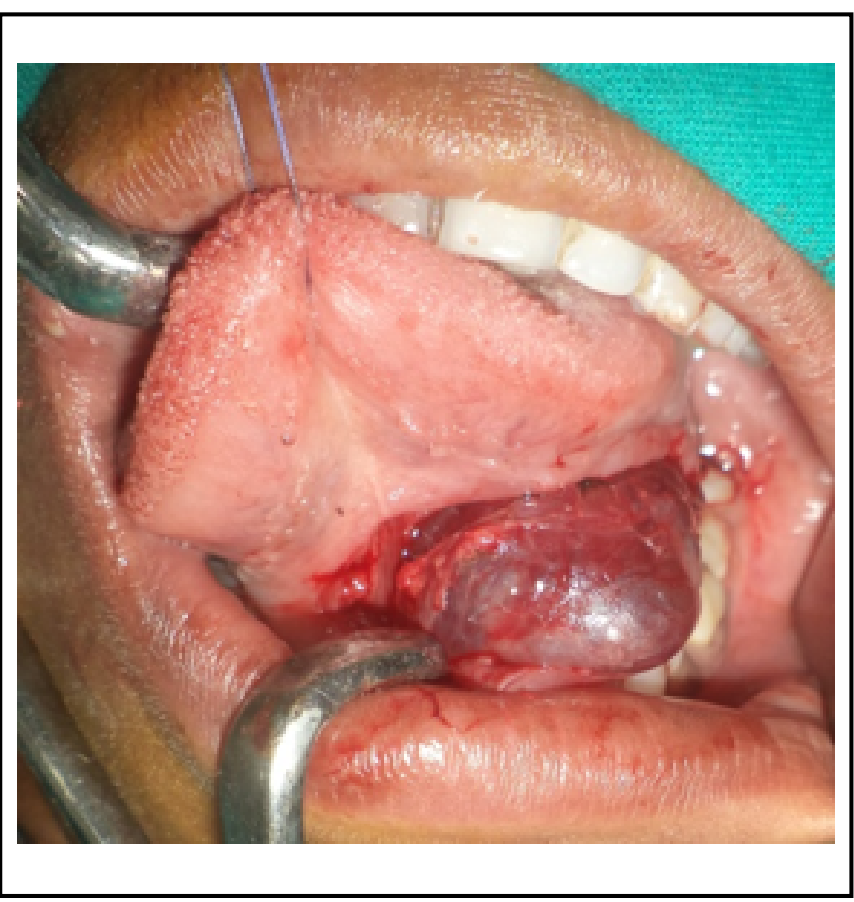

Fig. 1. Intra-operative picture showing ranula after elevation of mucosa

2014 to 31st March, 2019. Patients presenting with ranula irrespective of age and sex; size of the mass; whether primary or recurrent case were included in the study. Patients presenting with congenital and plunging ranula were excluded. Diagnosis of ranula was done based on history, clinical examination, USG of floor of mouth and neck, and FNAC. Patients were treated with total excision of ranula along with sublingual salivary gland.

Operation was performed under general anaesthesia after doing all routine pre-operative investigations. Patient was placed in supine position with slight elevation of the head end. The oral cavity was kept open using Doyens mouth gag. Tongue was held out using stay sutures. The mucosa over the ranula was incised taking care not to enter the sac. A plane of dissection in the submucosa was established over the wall of the ranula (Fig. 1). Bleeding was controlled using bipolar diathermy. Using sharp and blunt dissections, the cyst was excised along with sublingual salivary gland taking care not to damage submandibular duct and lingual nerve (Figs. 2, 3). The wound was closed loosely with

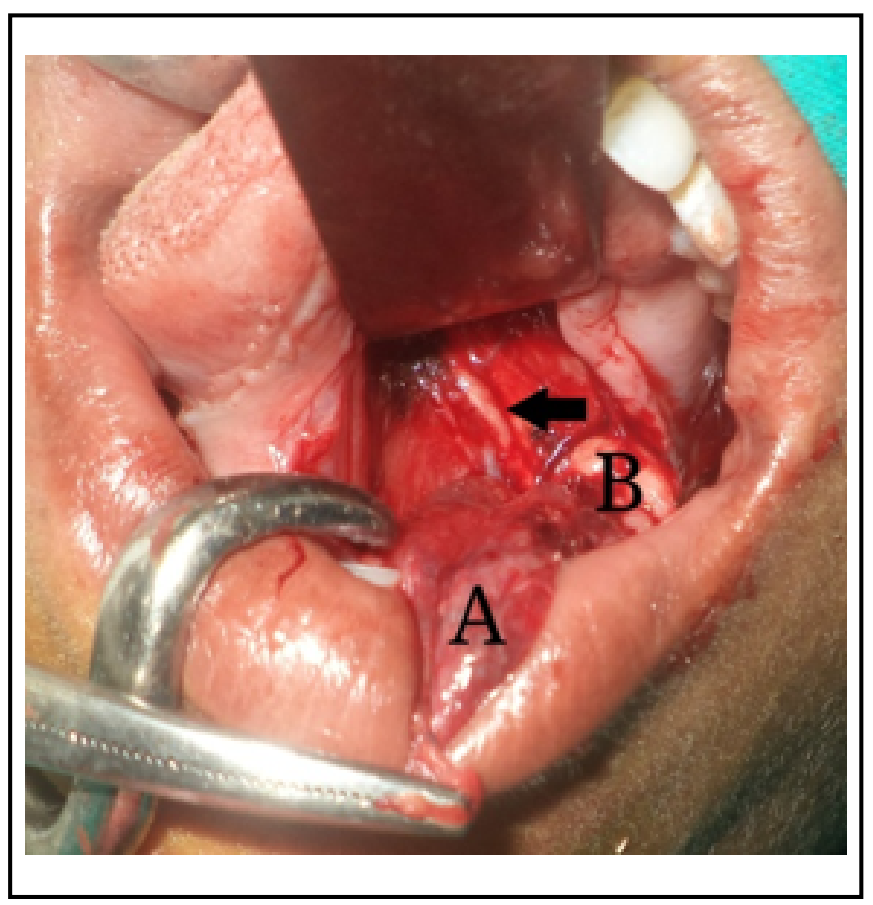

Fig. 2. Intra-operative picture showing ranula (A) along with sublingual salivary gland (B) and lingual nerve (black arrow)

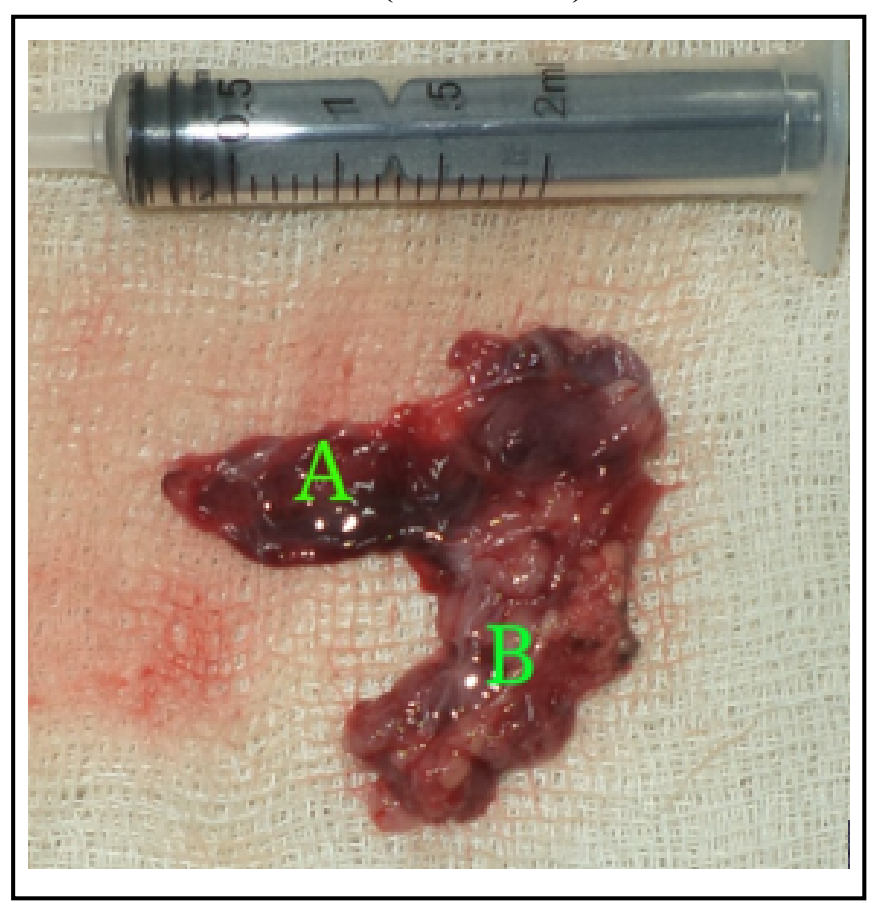

Fig. 3. Specimen of ranula (A) and sublingual salivary gland (B) after removal 
Table I: Distribution of patients according to age

\begin{tabular}{|c|c|}
\hline AGE GROUP (IN YEARS) & NUMBER OF PATIENTS \\
\hline $0-9$ & 5 \\
\hline $10-19$ & 6 \\
\hline $20-29$ & 4 \\
\hline $30-39$ & 2 \\
\hline
\end{tabular}

3-0 Vicryl ${ }^{\circledR}$ sutures. Patients were followed up regularly for at least one year post-operatively.

\section{Results}

During the study period total seventeen patients were operated for ranula. Among them eight were male and nine were female. Patients were from seven to thirty three years of age. Maximum numbers of patients were in the second decade of life (Table I). There was history of surgical intervention for same disease in four patients. Twelve patients had ranula in right side and five patients had in left side of floor of mouth. There was no injury to lingual nerve or submandibular duct in any patient. Wound healing was good in all patients. Till date no recurrence has occurred.

\section{Discussion}

"Ranula" was first reported by Hippocrates and Celsius. ${ }^{5}$ The current knowledge domain reveals that ranulas originate primarily from the sublingual salivary gland. Trauma to the sublingual gland duct leads to mucus extravasation and subsequent accumulation of saliva, and pseudocyst formation. ${ }^{6}$ Ranula is a rare surgically amenable disease of the salivary glands as described by various researchers. ${ }^{7}$ Rarity of the disease may be responsible for the dearth of literature on the subject. More so, several studies by most scholars have been case reports. ${ }^{8}$ The present study was done in a tertiary care hospital, where cases are referred from several districts. Nevertheless, we found only seventeen patients including both primary and recurrent cases in five years study period. Studies including those of Chidzonga et al. and Zhao et al reported female gender predilection with no clear scientific basis. ${ }^{9} 10$ In the present study ratio of male and female patients was 1:1.13. Simple ranula is common during the first and second decade of life. ${ }^{11}$

In the present study maximum numbers of patients were in the second decade of life. The differential diagnosis of simple ranula encompasses a host of lesions like lipoma, dermoid cyst, salivary gland tumours, hemangioma, and lymphangioma. ${ }^{12}$ The diagnosis is often a clinical one based on typical history and appearance of mass. Imaging helps in confirming the diagnosis and ascertaining the neck extension if present. ${ }^{13}$ There is no consensus opinion on the definitive management of ranula. Multiple options exist, including surveillance, needle aspiration, surgical excision of the cyst, excision of sublingual gland with or without the cyst, marsupialisation, sclerotherapy, laser excision or cryosurgery. ${ }^{14,15}$ However, different outcomes have been reported with each approach having varying complications. Recurrence has been reported to be the main concern.

In earlier days the most common technique used was marsupialisation. It had high recurrence rate of $61 \%-89 \%$ as the cyst was not completely excised. In some instances, it served as a precursor for plunging ranula. ${ }^{16}$ In order to evade this problem, Yang and Hong recommended removing the cyst along with the sublingual gland. ${ }^{13}$ Crysdale et al. reported that the recurrence rate was $100 \%$ in cases with incision and drainage, $61 \%$ in cases 
of simple marsupialization, and $0 \%$ in case of excision of the ranula with or without sublingual gland excision. ${ }^{1}$ In a study, Sigismund et al. in a retrospective analysis of 65 patients reported a recurrence prevalence of $3.6 \%$ following complete excision of the sublingual gland alone compared with $36.7 \%$ prevalence with ranula excision alone. ${ }^{17}$ Zhao and co-workers concur that recurrence rates of ranula excisions are excessive unless the sublingual gland is removed. ${ }^{10} \mathrm{~A}$ sublingual gland excision involves the potential risk for injury to the Wharton's duct, obstruction of submandibular gland, lingual nerve injury. We treated thirteen primary and four recurrent cases of ranula with complete excision of ranula along with sublingual salivary gland. We did not observe any recurrence till date. Many-a-times ranula bursts spontaneously or during operation. This doesn't pose any difficulty in complete excision of the cyst. We did not come across any injury to submandibular duct and lingual nerve. The only drawback of this procedure, in our opinion is longer time of operation as compared to simpler techniques.

\section{Conclusion}

Ranula is a rare surgically amenable disease of the salivary glands. Though it is benign condition, it is notorious for recurrence. Successful management of a ranula includes identification of the extent of the cyst and removal of the cyst along with the sublingual salivary gland. When done meticulously, this technique gives $100 \%$ success without any complication.

\section{References}

1. Crysdale WS, Mendelsohn JD, Conley S. Ranulas - Mucoceles of the oral cavity: Experience in 26 children. Laryngoscope 1988; 98(3):296-8
2. Zhi K, Wen Y, Ren W, Zhang Y. Management of infant ranula. Int J Pediatr Otorhinolaryngol. 2008; 72:823-6

3. Bronstein SL, Clark MS. Sublingual gland salivary fistula and sialocele. Oral Surg Oral Med Oral Pathol. 1984; 57(4):357-61

4. Regezi JA, Sciubba JJ, Jordan RCK. Oral pathology, clinical pathologic correlations. In: Regezi JA, Sciubba JJ, eds. 3rd ed. Philadelphia: WB Saunders Company; 1999:220-222

5. Cedric A.Q; Seth HL. Ranula and the Sublingual Salivary Glands. Arch Otolaryngol. 1977; 103(7):397-400

6. Harrison JD. Modern management and pathophysiology of ranula: Literature review. Head Neck 2010; 32:1310-20

7. Rho MH, Kim DW, Kwon SS et al (2006). OK-432 Sclerotherapy of plunging ranula in 21 patients. It can be a substitute for surgery. AJNR Am J Neuroradiol. 2006; 27(5):1090-5

8. Dayton K, Ryan MF. Symptomatic floor of mouth swelling with neck extension in a 14 year-old girl. Case Rep Pediatr. 2014; 2014:8319-23

9. Chidzonga MM, Rusakaniko S. Ranula: another HIV/ AIDS associated oral lesion in Zimbabwe. Oral Dis. 2004; 10:229-32

10. Zhao YF, Jia Y, Chen XM et al. Clinical review of 580 ranulas. Oral Surg Oral Med Oral Pathol Oral Radiol Endod. 2004; 98:281-7

11. Batsakis JG, McClatchey KD. Cervical ranulas. Ann Otol Rhinol Laryngol. 1988; 97:561-2

12. Shafer WG, Hine MK, Levy BM. A text book of oral pathology. Philadelphia: WB Saunders; 2009;6:543

13. Yang Y, Hong K. Surgical results of the intraoral approach for plunging ranula. Acta Otolaryngol (Stockh). 2014; 134(2):2015

14. Patel MR, Deal AM, Shockley WW. Oral and plunging ranulas: What is the most effective treatment? Laryngoscope 2009; 119:1501-9

15. Zhi K, Gao L, Ren W. What is new in management of pediatricranula? Curr Opin Otolaryngol Head Neck Surg. 2014; 22(6):525-9

16. Haberal I, Gocmen H, Samim E. Surgical management of ranula. Int J Paediatr Otorhinolaryngol. 2004;68:161-3

17. Sigismund PE, Bozzato A, Schumann M, et al (2013). Management of ranula: 9 years' clinical experience in pediatric and adult patients. J Oral Maxillofac Surg. 2013; 71(3):538-44. 